Georgia State University

ScholarWorks @ Georgia State University

\title{
The role of psychological flexibility in the relationship between self-concealment and disordered eating symptoms
}

Akihiko Masuda

Georgia State University, amasuda@gsu.edu

M. S. Boone

C. A. Timko

Follow this and additional works at: https://scholarworks.gsu.edu/psych_facpub

Part of the Psychology Commons

\section{Recommended Citation}

Masuda, Akihiko; Boone, M. S.; and Timko, C. A., "The role of psychological flexibility in the relationship between self-concealment and disordered eating symptoms" (2011). Psychology Faculty Publications. 93. https://scholarworks.gsu.edu/psych_facpub/93

This Article is brought to you for free and open access by the Department of Psychology at ScholarWorks @ Georgia State University. It has been accepted for inclusion in Psychology Faculty Publications by an authorized administrator of ScholarWorks @ Georgia State University. For more information, please contact scholarworks@gsu.edu. 
Running head: SELF-CONCEALMENT AND DISORDERED EATING SYMPTOMS

The Role of Psychological Flexibility in the Relationship between Self-Concealment and Disordered Eating Symptoms

\author{
Akihiko Masuda \\ Georgia State University \\ Matthew S. Boone \\ Cornell University \\ C. Alix Timko \\ University of the Sciences
}

Author Note

Akihiko Masuda, Department of Psychology, Georgia State University; Matthew

S. Boone, Counseling and Psychological Services, Cornell University; C. Alix Timko, Department of Behavioral and Social Sciences, University of the Sciences

Correspondence regarding this article should be addressed to Akihiko Masuda, Department of Psychology, Georgia State University, Atlanta, GA 30303, USA. Email Address: psyaxm@langate.gsu.edu 


\begin{abstract}
The present cross-sectional study investigated whether psychological flexibility mediates the association between self-concealment and disordered eating (DE) symptoms among non-clinical college students. Data of 209 male and female participants ( $n f_{\text {emale }}=$ 165), aged 18-22 years old, were used for analyses. Self-concealment was found to be positively associated with DE symptoms (i.e., general eating disorder symptoms and eating disorder-related cognitions) and negatively associated with psychological flexibility. Psychological flexibility was inversely associated with DE symptoms. Finally, psychological flexibility was found to mediate the association between self-concealment and DE symptoms after accounting for gender, ethnic background, and body mass index (BMI).
\end{abstract}

Key Words: Psychological Flexibility, Eating Disorder, Disordered Eating, SelfConcealment. 
1. Introduction

Disordered eating (DE) symptoms, defined as general eating disorder pathology and eating disorder-related cognition, is increasingly common among adolescents and younger adults (e.g., Grabe, Ward, \& Hyde, 2008; Striegel-Moore \& Bulik, 2007), including college students (Vohs, Heatherton, \& Herrin, 2001). While only a small number of college students meet the clinical criteria for an eating disorder (Hudson, Hiripi, Pope, \& Kessler, 2007), many of them, especially women, experience some constellation of DE symptoms, such as negative body image, dieting, exercise, and compensatory behaviors (e.g., Mintz \& Betz, 1988). Although historically European American women have been the primary target of college programming to reduce disordered eating and body dissatisfaction, recent evidence indicates that male students (Cooper, 2006; Lavender \& Anderson, 2010; Timko, Mooney, \& Juarascio, 2010) and ethnic minority college females (e.g., Rogers \& Petrie, 2010; Mintz \& Kashubeck, 1999) endorse DE symptoms as well.

Many factors are theorized to contribute to the development and maintenance of DE symptoms (Fairburn, 2008; Fairburn, Cooper, \& Shafran, 2003; Striegel-Moore \& Bulik, 2007). One factor that has not been fully investigated is a dispositional tendency to keep personal information from others. Literature has suggested that individuals diagnosed with an eating disorder tend to distort or withhold information about their eating, amount of exercise, purging, drive for thinness, and negative body image (Pryor, Johnson, Wiederman, \& Bowwell, 1995), and employ a variety of strategies to do so (Vandereycken, \& Humbeeck, 2008). 
Self-concealment, a general and stable behavioral tendency to keep distressing and potentially embarrassing personal information from others (Larson \& Chastain, 1990), is a construct that is particularly relevant to this area of research. According to Larson and Chastain (1990), self-concealment involves multiple processes, including possessing a troubling and negatively evaluated secret, keeping it from others, and avoiding or feeling apprehensive about self-disclosure. Research has shown that selfconcealment is positively associated with various negative behavioral and health outcomes, including negative affect (e.g., Kahn \& Hessling, 2001; Larson \& Chastain, 1990), psychological distress (Cramer, 1999; Kelly \& Yip, 2006; Masuda, Anderson, \& Sheehan, 2009), pain and headaches (Larson \& Chastain, 1990), and many others (e.g., Kawamura \& Frost, 2004).

Although the evidence is limited, there is likely a relationship between selfconcealment and DE symptoms. One study revealed that self-disclosure, which by definition is antithetical to self-concealment, was inversely related to eating disorder symptoms and associated factors, such as body dissatisfaction, dieting, and perceived social pressure to be thin (Basile, 2004). Another study reported that women with more DE symptoms were less willing to self-disclose certain personal details (e.g., relationships, DE symptoms, daily activities) than women with fewer DE symptoms (Evans \& Wertheim, 2002).

While these findings are informative, it is still unclear why self-concealment relates to DE symptoms. Given the existing evidence (Lavender \& Anderson, 2010; Masuda, Anderson, et al., 2009; Masuda, Wendell, Chou, \& Feinstein, 2010; Wismeijer, van Assen, Sijtsma, \& Vingerhoets, 2009), it may be that self-concealment and DE 
symptoms are linked by a shared feature: maladaptive avoidance-based coping strategies. Self-concealing individuals often inhibit and suppress potentially embarrassing personal information and painful psychological experiences as a means of down-regulating negative affect (e.g., Farber, Berano, \& Capobianco, 2004). However, such attempts can paradoxically amplify negative affect (Wegner, 1994), which in turn further strengthens the maladaptive coping strategies (Hayes, Wilson, Gifford, Follette, \& Strosahl, 1996). For example, one study showed that women with eating disorders who role-played not having an eating disorder (i.e., suppressed) experienced more intrusive thoughts and required greater effort to suppress than other women when answering questions about body image, eating habits, and weight (Smart \& Wegner, 1999). Similarly, literature on affect regulation models posits that DE symptoms such as binging, purging, and restriction function as maladaptive efforts to modulate or escape from aversive emotional states (Christiano \& Mizes, 1997; Ghaderi, 2003; Lavender \& Anderson, 2010; Stice, Nemeroff, \& Shaw, 1996). These behaviors inevitably generate further aversive emotional states, which precipitate further disordered behavior.

\subsection{Diminished Psychological Flexibility}

This explanation parallels the model of psychological flexibility, a contemporary behavioral account of psychological wellbeing (Hayes, Luoma, Bond, Masuda, \& Lillis, 2006). According to Hayes et al. (2006), psychological flexibility is "the ability to contact the present moment fully as a conscious human being, and to change or persist in behavior when doing so serves valued ends” (p. 7). It is an overarching behavioral process of experiencing whatever one is experiencing as it is fully and non-judgmentally without defense or judgment in addition to engaging in value-directed activities. The 
model also states that diminished psychological flexibility, which is characterized by maladaptive self-rules, avoidance, and suppression, is at the core of various forms of psychopathology.

Evidence indicates that diminished psychological flexibility is a generalized diathesis (Kashdan, Barrios, Forsyth, \& Steger, 2006) associated with a wide range of negative psychological outcomes, including depressive symptoms (e.g., Bond \& Bunce, 2000), anxiety (e.g., Kashdan et al., 2006), general psychological ill-health (e.g., Bond \& Bunce, 2003; Masuda, Anderson et al., 2009), and emotional distress in stressful interpersonal contexts (Masuda, Price, Anderson, Schmertz, \& Calamaras, 2009). Although the evidence is still limited, psychological flexibility is found to be inversely related to self-concealment (Masuda, Anderson et al., 2009; Masuda et al., 2011), cognitive aspects of DE symptoms (Masuda, Price, Anderson, \& Wendell, 2010; Masuda \& Wendell, 2010), and general eating disorder pathology (Rawal, Park, \& Williams, 2010).

\subsection{Present Study}

Though this literature suggests a relationship between self-concealment and DE symptoms, one which might explained in part by diminished psychological flexibility, no study has yet clearly established this link. The purpose of the present study was to examine whether self-concealment was related to DE symptoms and, if so, whether the relationship was mediated in part by psychological flexibility. Based on prior findings (e.g., Basile, 2004; Masuda, Price et al., 2010), it was hypothesized that self-concealment would be positively related to DE symptoms (i.e., general eating disorder pathology and eating disorder-related cognitions) and inversely related to psychological flexibility. 
Conversely, psychological flexibility was hypothesized to be inversely associated with DE symptoms. Finally, it was hypothesized that diminished psychological flexibility would at least partially mediate the associations between self-concealment and ED symptoms after accounting for gender, ethnicity, and body mass index (BMI), factors found to be strongly associated with DE symptoms (Striegel-Moore \& Bulik, 2007).

\section{Method}

\subsection{Participants}

The present study was conducted at a large, public 4-year university in Georgia. Participants were recruited from undergraduate psychology courses through a web-based research survey tool. Two hundred and ninety-four participants $\left(76 \%, n_{\text {Female }}=223\right)$ completed a survey package that contained multiple self-report measures. The mean completion time for the package was approximately 30 minutes $(S D=15.23)$. Sixty participants who completed the survey in either less than 15 minutes or more than 45 minutes were excluded because of the questionable validity of their responses. The age of the remaining participants ranged from 17 to 46 years old $(M=20.35, S D=3.96)$. Based on outlier analysis of age, one 17 year-old participant and 24 participants aged 23 or older were also removed from the study.

As a result, the final sample consisted of 209 participants $\left(79 \%, n_{\text {Female }}=165\right)$ aged 18 to 22 with an average body mass index (BMI) of $23.19(S D=4.82)$. The ethnic composition of the sample was fairly representative of the college where the university is located, with 47\% $(n=99)$ identifying as "European American,” 25\% $(n=52)$ identifying as “African American,” 17\% $(n=35)$ identifying as “Asian American/Pacific 
Islander," 4\% $(n=8)$ identifying as "Hispanic American,” and 7\% $(n=15)$ identifying as "bicultural” or "other."

\subsection{Measures and Procedure}

Participants who enrolled in the study were asked to complete an anonymous web-based survey. Prior to beginning the survey, the purpose of the study and instructions for responding were presented. Participants anonymously provided demographic information and completed the measures. The present study was approved by the Institutional Review Board of the university. The following measures were administered to assess self-concealment, psychological flexibility, general eating disorder pathology, and eating disorder-related cognitions.

\subsubsection{Self-Concealment}

The Self Concealment Scale (SCS; Larson \& Chastain, 1990) is a self-report inventory designed to measure a person's tendency to conceal personal information that is distressing or negatively-evaluated (e.g., "There are lots of things about me that I keep to myself”). The SCS contains 10 items and employs a 5-point Likert scale ranging from 1 (strongly disagree) to 5 (strongly agree) for each item. The total score is derived from the sum of responses to all 10 items, with greater values indicating greater self-concealment. The SCS is a reliable measure of self-concealment, with test-retest (over 4 weeks) and inter-item reliability estimates of .81 and .83, respectively (Larson \& Chastain, 1990). In the present study, Cronbach’s alpha was .89.

\subsubsection{Psychological Flexibility}

The Acceptance and Action Questionnaire-16 item (AAQ-16; Bond \& Bunce, 2003) was used to measure psychological flexibility. The AAQ is a 16-item questionnaire 
designed to assess willingness to accept undesirable thoughts and feelings (e.g., "It is OK to feel depressed or anxious”), while acting in a way that is congruent with one's values and goals (e.g., "I am able to take action on a problem even if I am uncertain of the right thing to do”). The measure employs a 7-point Likert scale, ranging from 1 (never true) to 7 (always true). Total scores range from 16 to 112, with higher scores indicating greater psychological flexibility. Research has indicated that the AAQ has good psychometric properties (see Hayes, Strosahl et al., 2004). In a previous study conducted with a nonclinical sample (Bond \& Bunce, 2003), Cronbach’s alpha for this measure ranged from .72 to .79. In the current study, Cronbach’s alpha was .64.

\subsubsection{General Eating Disorder Pathology.}

The 26-item version of the Eating Attitudes Test (EAT-26; Garner, Olmstead, Bohr, \& Garfinkel, 1982) is a self-report inventory that measures general eating disorder pathology (e.g., "I am terrified about being overweight” and “I vomit after I have eaten”). Each of the 26 items is scored on a 6-point Likert scale: never (0), rarely (0), sometimes (0), often (1), very often (2), or always (3). The total score ranges from 0 to 78, with higher scores reflecting greater eating disorder symptomomatology. In a previous study conducted with non-clinical samples of female college students (Mazzeo, 1999), Cronbach’s alpha coefficient for the measure was .91. In the current study, Cronbach’s alpha was .85.

\subsubsection{Eating Disorder-Related Cognition}

The Mizes Anorectic Cognitions Questionnaire-Revised (MAC-R; Mizes et al., 2000) is a 24-item self-report questionnaire designed to assess distorted cognitions related to all eating disorders. These cognitions include the fear of weight gain (e.g., "If I 
don’t establish a daily routine, everything will be chaotic, and I won’t accomplish anything”), the importance of being thin or attractive to social acceptance ("No one likes fat people; therefore, I must remain thin to be liked by others”), and the relationship between controlled eating and weight gain ("If my weight goes up, my self-esteem goes down”). Each item is scored on a 5-point Likert scale, ranging from 1 (strongly disagree) to 5 (strongly agree), with a total score derived from the sum of all responses. Total scores range from 24 to 120, with higher scores indicating greater eating disorder-related dysfunctional cognitions. In a previous study conducted with clinical samples with various eating disorders (Mizes et al., 2000), Cronbach’s alpha coefficient for the MACR total was .90. In the present study, Cronbach’s alpha was .89.

\section{Results}

\subsection{Correlations among Study Variables}

Descriptive statistics and correlations among the variables are shown in Table 1. Gender ( 1 = male, 2 = female $)$ and ethnicity $(1=$ Non-Hispanic European American, 2 = Ethnic minority) were dichotomously categorized for the correlational analyses. Selfconcealment (SCS) was positively related to general eating disorder pathology (EAT-26) and eating disorder-related cognition (MAC-R) and inversely related to psychological flexibility (AAQ-16). Psychological flexibility was negatively related to general eating disorder pathology and eating disorder-related cognition. Furthermore, general eating disorder pathology was positively associated with eating disorder-related cognition. Being female or a person from an ethnic minority background was found to be linked to greater self-concealment. Being female was also found to be related to lower psychological flexibility. 


\subsection{Psychological Flexibility as a Mediator of Self-Concealment and General Eating} Disorder Pathology

Based on the guidelines of Baron and Kenny (1986), a series of linear regression analyses were conducted to examine whether psychological flexibility mediated the relationship between self- concealment and two dependent variables, general eating disorder pathology and eating disorder-related cognition, after accounting for gender, ethnicity, and BMI. The analyses revealed a significant A path between self-concealment and psychological flexibility $(\beta=-.44, p<.001)$, a significant B path between psychological flexibility and general eating disorder pathology $(\beta=-.33, p<.001)$, and a significant $\mathrm{C}$ path between self-concealment and general eating disorder pathology $(\beta=$ $.22, p<.01)$. Table 2 shows the results of the final step of mediation analyses, which revealed that the relationship between self-concealment and general eating disorder pathology was no longer significant when psychological flexibility was taken into account. These findings suggest that the relationship between self-concealment and general eating disorder pathology is established in part through diminished psychological flexibility.

3.3. Psychological Flexibility as a Mediator of Self-Concealment and Eating Disorderrelated Cognitions

A series of linear regression analyses revealed a significant A path between selfconcealment and psychological flexibility, a significant B path between psychological flexibility and eating disorder-related cognition $(\beta=-.47, p<.001)$, and a significant $\mathrm{C}$ path between self-concealment and eating disorder-related cognition $(\beta=.37, p<.001)$. As shown in Table 2, the results revealed that psychological flexibility only partially 
mediated the relationship between self-concealment and eating disorder-related cognition (final $\beta=.20, p<.01$ ). The conservative Sobel test of mediation suggests that psychological flexibility accounted for a significant relationship between selfconcealment and eating disorder-related cognition $(z=4.30, p<.001)$.

\section{Discussion}

The purpose of the present study was to examine whether self-concealment was positively related to DE symptoms and, if so, whether psychological flexibility at least partially mediated the relationship. As predicted, self-concealment was positively associated with DE symptoms (i.e., general eating disorder pathology and eating disorder-related cognitions), such that those with greater self-concealment tended to have greater DE symptoms. Furthermore, self-concealment was inversely associated with psychological flexibility, which in turn was negatively related to DE symptoms. Finally, diminished psychological flexibility was found to at least partially mediate the associations between self-concealment and DE symptoms. These results suggest that the link between self-concealment and DE symptoms is established in part through the shared feature of diminished psychological flexibility.

The present findings extend the existing literature on secrecy and disordered eating. Concealment of one's eating disorder has been reported in both qualitative studies (e.g., Huke \& Slade, 2006; Pettersen, Rosenvinge, \& Ytterhus, 2008) and quantitative research (e.g., Basile, 2004; Evans \& Wertheim, 2002; Vandereycken \& van Humbeek, 2008). Some studies also suggest shame and stigma drive concealment of eating disorders (Huke \& Slade, 2006; Pettersen, et al., 2008); others point to denial of the disorder (Vandereycken \& van Humbeeck, 2008). Both hypotheses assume that individuals with 
eating disorders cannot tolerate negative thoughts and feelings, leading them to conceal them from themselves and/or others.

This intolerance is characteristic of diminished psychological flexibility (Hayes et al., 2006). Diminished psychological flexibility has been hypothesized to play a role in maintaining eating disorders (Schmidt \& Treasure, 2006) and is consistent with emotional regulation models of eating disorders (Christiano \& Mizes, 1997; Ghaderi, 2003; Heffner \& Eifert, 2004; Lavender \& Anderson, 2010; Stice, Nemeroff, \& Shaw, 1996). Emotion regulation models suggest DE symptoms can be understood in terms of maladaptive emotion regulation strategies. For example, a common symptom like fear of gaining weight is likely to engender negative affect. An individual with an eating disorder will engage in compensatory behaviors, such as purging or over exercising to cope with negative affect (Christiano \& Mizes, 1997; Ghaderi, 2003). These behaviors bring an immediate, short-term reduction in distress, which reinforces them. However, this pattern often results in more psychological distress (e.g., shame, guilt, more anxiety about one's body), which precipitates more compensatory behaviors and establishes a vicious cycle (Heffner \& Eifert, 2004).

Previous studies found that keeping secrets is not inherently toxic to psychological health (Kelly \& Yip, 2006), but becomes detrimental once it turns into an affect regulation pattern (Wismeijer et al., 2009; Masuda et al., 2011). The inverse relationship between self-concealment and psychological flexibility found in the current study adds nuance to this evidence. The construct of psychological flexibility is part of a contemporary behavioral conception of psychopathology (Hayes, Strosahl, \& Wilson, 1999) and emphasizes patterns of emotion and behavior regulation. It is speculated that 
greater self-concealment is associated with greater DE symptoms when it serves as part of a narrow repertoire of affect regulation.

The construct of psychological flexibility also carries with it an emphasis on the importance of the function of behaviors. Conventional models of eating disorders (e.g., Wonderlich, Joiner, Keel, Williamson, \& Crosby, 2007) typically place greater emphasis on the type and frequency of symptoms, as well as their hypothesized etiology, and less emphasis on how they are functionally maintained (Rawal et al., 2010). However, recent findings in empirical clinical psychology suggest that the functional link between difficult psychological events (e.g., negative affect) and responses to these events (e.g., regulation strategies) often accounts for psychological health more than the presence of these events (Hayes et al., 2006; Kashdan et al., 2006). Given the present findings, it is worthwhile to investigate whether this is the case with DE symptoms.

Targeting the function of eating disorder behavior is consistent with the recent acceptance- and mindfulness-based approaches in clinical psychology (e.g., Hayes, Follette, \& Linehan, 2004), where the focus is often placed on altering the functional relationship between painful internal experiences and one's responses to these experiences. These therapies are designed to build psychological flexibility around unpleasant thoughts and feelings rather than attempting to control or down-regulate them (e.g., Segal, Teasdale, \& Williams, 2004; Teasdale et al., 2002). Preliminary evidence indicates that acceptance-based interventions are effective in altering disordered eating behavior and in promoting psychological health (e.g., Baer, Fischer, \& Huss, 2005; Heffner \& Eifert, 2004; Juarascio, Forman, \& Herbert, 2010; Masuda, Muto, Hayes, \& Lillis, 2008; Merwin, et al., 2010; Safer, Telch, \& Agras, 2001; Telch, Agras, \& Linehan, 
2001). The results of the current study indicate that decreased psychological flexibility can help to explain the functional relationship between avoidant behaviors -- including self-concealment -- and disordered eating. Given the increasing evidence that reduced psychological flexibility plays a role in the maintenance of DE symptoms, it is worthwhile to continue to investigate the theory and practice of acceptance-based interventions to promote the understanding and treatment of DE symptoms.

A somewhat surprising set of findings in the present study were that gender, ethnicity, and BMI were not predictors of DE symptoms. Although a deeper investigation is beyond the scope of this study, we speculate that these findings were in part due to the use of heterogeneous sample of non-clinical college students. Unlike other studies, male and female participants were combined and over $50 \%$ of the participants self-identified as being from an ethnic minority group.

The present investigation had several limitations. The study is limited in conceptual scope and clinical significance. It was a theoretical investigation designed to gain a preliminary understanding of the association between self-concealment and DE symptoms, as well as psychological flexibility's mediating role, in a nonclinical sample of college undergraduates. Therefore, this study is suggestive and should not be treated as a report on eating disorder psychopathology observed in a clinical sample. Additionally, as discussed elsewhere (e.g., Striegel-Moore \& Bulik, 2007), it is important to note that there are other risk factors which account for the development and maintenance of DE symptoms and they seem to do so more than self-concealment. The study did not investigate the role of psychological flexibility in the link between self-concealment and DE symptoms while controlling for these variables, including neuroticism (Tylka, 2004), 
social perfectionism (Brannan \& Petrie, 2008; Tylka, 2004), and overemphasis of body shape and weight (Fairburn, 2008).

Finally, the current study relied on a cross-sectional and correlational design with the use of self-report measures. This analytic strategy did not allow us to derive any causal inferences or functional links among the events of our interest (i.e., selfconcealment, DE symptoms, psychologically flexible behavior, and negative behavioral consequences). To date, the development and refinement of appropriate methods for capturing the functional link among these phenomena is quite challenging. A potential method may be the repeated behavioral assessment of well-defined psychologically flexible coping behavior, self-concealment, and DE symptoms in the context of an analog experiment and perhaps a treatment intervention. Although the application of such behavioral measurement seems challenging, the effort would be warranted.

Despite these limitations, the present study adds additional evidence regarding the relationships among self-concealment, DE symptoms, and psychological flexibility. It also suggests that it is worthwhile to consider DE symptoms and their relationship to self-concealment in terms of the construct of psychological flexibility. 


\section{References}

Baer, R. A., Fischer, S., \& Huss, D. B. (2005). Mindfulness and acceptance in the treatment of disordered eating. Journal of Rational-Emotive \& CognitiveBehavior Therapy, 23, 281-300.

Basile, B. (2004). Self-disclosure in eating disorders. Eating and Weight Disorders, 9(3), 217-223.

Bond, F. W., \& Bunce, D. (2000). Mediators of change in emotion-focused and problemfocused worksite stress management interventions. Journal of Occupational Health Psychology, 5, 156-163.

Bond, F. W., \& Bunce, D. (2003). The role of acceptance and job control in mental health, job satisfaction, and work performance. Journal of Applied Psychology, 88, $1057-1067$.

Brannan, M. E., \& Petrie, T. A. (2008). Moderators of the body dissatisfaction-Eating disorder symptomatology relationship: Replication and Extension. Journal of Counseling Psychology, 55, 263-275.

Christiano, B., \& Mizes, J. (1997). Appraisal and coping deficits associated with eating disorders: Implications for treatment. Cognitive and Behavioral Practice, 4(2), 263-290.

Cooper, M. J. (2006). Beliefs and their relationship to eating attitudes and depressive symptoms in men. Eating Behaviors, 7, 423-426.

Cramer, K. M. (1999). Psychological antecedents to help-seeking behavior: A reanalysis using path modeling structures. Journal of Counseling Psychology, 46, 381-387. 
Evans, L., \& Wertheim, E. (2002). An examination of willingness to self-disclose in women with bulimic symptoms considering the context of disclosure and negative affect levels. International Journal of Eating Disorders, 31(3), 344-348.

Fairburn, C. G. (Eds.). (2008). Cognitive behavior therapy and eating disorders. New York: The Guilford Press.

Fairburn, C. G., Cooper, Z., \& Shafran, R. (2003). Cognitive behaviour therapy for eating disorders: A “transdiagnostic” theory and treatment. Behaviour Research and Therapy, 41, 509-528.

Farber, B. A., Berano, K. C., \& Capobianco, J. A. (2004). Clients’ perceptions of the process and consequences of self-disclosure in psychotherapy. Journal of Counseling Psychology, 51, 340-346.

Garner, D. M., Olmsted, M. P., Bohr, Y., \& Garfinkel, P. E. (1982). The Eating Attitudes Test: Psychometric features and clinical correlates. Psychological Medicine, 12, 871-878.

Ghaderi, A. (2003). Structural modeling analysis of prospective risk factors for eating disorder. Eating Behaviors, 3(4), 387-396.

Grabe, S., Ward, L. M., \& Hyde, J. S. (2008). The role of the media in body image concerns among women: A meta-analysis of experimental and correlational studies. Psychological Bulletin, 134, 460-476.

Hayes, S. C., Follette, V. M., \& Linehan, M. M. (Eds.) (2004). Mindfulness and acceptance: Expanding the cognitive behavioral tradition. New York: Guilford Press. 
Hayes, S. C., Luoma, J., Bond, F., Masuda, A., \& Lillis, J. (2006). Acceptance and Commitment Therapy: Model, processes and outcomes. Behaviour Research and Therapy, 44, 1-25.

Hayes, S. C. Strosahl, K. D., \& Wilson, K. G. (1999). Acceptance and Commitment Therapy: An experiential approach to behavior change. New York: Guilford Press.

Hayes, S. C., Strosahl, K. D., Wilson, K. G., Bissett, R. T., Pistorello, J., Toarmino, D., et al. (2004). Measuring experiential avoidance: A preliminary test of a working model. The Psychological Record, 54, 553-578.

Hayes, S. C., Wilson, K. G., Gifford, E. V., Follette, V. M., \& Strosahl, K. (1996). Emotional avoidance and behavioral disorders: A functional dimensional approach to diagnosis and treatment. Journal of Consulting and Clinical Psychology, 64, 1152-1168.

Heffner, M., \& Eifert, G. H. (2004). The anorexia workbook: How to accept yourself, heal suffering, and reclaim your life. Oakland, CA: New Harbinger Publications.

Hudson, J. I., Hiripi, E., Pope, H. G., Kessler, R. C. (2007). The prevalence and correlates of eating disorders in the national comorbidity survey replication. Biological Psychiatry, 61, 348-358.

Huke, K. \& Slade, P. (2006). An exploratory investigation of the experiences of partners living with people who have bulimia nervosa. European Eating Disorders Review, 14, 436-447. 
Juarascio, A. S., Forman, E. M., \& Herbert, J. D. (2010). Acceptance and commitment therapy versus cognitive therapy for the treatment of comorbid eating pathology. Behavior Modification, 34(2), 175-190.

Kahn, J. H., \& Hessling, R. M. (2001). Measuring the tendency to control versus disclose psychological distress. Journal of Social and Clinical Psychology, 20, 41-65.

Kashdan, T. B., Barrios, V., Forsyth, J. P., \& Steger, M. F. (2006). Experiential avoidance as a generalized psychological vulnerability: Comparisons with coping and emotional dysregulation strategies. Behaviour Research and Therapy, 44, 1301-1320.

Kawamura, K. Y., \& Frost, R. O. (2004). Self-concealment as a mediator in the relationship between perfectionism and psychological distress. Cognitive Therapy and Research, 28, 183-191.

Kelly, A. E., \& Yip, J. J. (2006). Is keeping a secret or being a secretive person linked to psychological symptoms? Journal of Personality, 74, 1349-1369.

Larson, D. G., \& Chastain, R. L. (1990). Self-concealment: Conceptualization, measurement, and health implications. Journal of Social and Clinical Psychology, 9, 439-455.

Lavender, J. M., \& Anderson, D. A. (2010). Contribution of emotion regulation difficulties to disordered eating and body dissatisfaction in college men. International Journal of Eating Disorders, 43, 352-357.

Masuda, A., Anderson, P. L., \& Sheehan, S. (2009). Mindfulness and mental health among African American college students. Complementary Health Practice Review, 14, 115-127. 
Masuda, A., Anderson, P. L, Wendell, J. W., Price, M., Feinstein, A. B., \& Chou, Y. (2011). Psychological flexibility mediates the relation between self-concealment and negative psychological outcomes. Personality and Individual Differences, 50, 243-247.

Masuda, A., Muto, T., Hayes, S. C., \& Lillis, J. (2008). Acceptance and Commitment Therapy: Application to a Japanese client. Japanese Journal of Behavior Therapy, 34, 137-148.

Masuda, A., Price, M., Anderson, P. L., Schmertz, S. K., \& Calamaras, M. R. (2009). The role of psychological flexibility in mental health stigma and psychological distress for the stigmatizer. Journal of Social and Clinical Psychology, 28, 1244-1262.

Masuda, A., Price, M., Anderson, P. L., \& Wendell, J. W. (2010). Disordered eatingrelated cognition and psychological flexibility as predictors of psychological health among college students. Behavior Modification, 34, 3-15.

Masuda, A., \& Wendell, J. W. (2010). The role of mindfulness on the relations between disordered eating-related cognition and psychological distress, Eating Behaviors, 11, 293-296.

Masuda, A., Wendell, J. W., Chou, Y., \& Feinstein, A. B. (2010). Relationships among self-concealment, mindfulness, and negative psychological outcomes in Asian American and European American college students. International Journal for the Advancement of Counseling, 31, 165-177.

Mazzeo, S. E. (1999). Modification of an existing measure of body image preoccupation and its relationship to disordered eating in female college students. Journal of Counseling Psychology, 49, 86-100. 
Merwin, R.M., Timko, C.A., Moskovich, A.A., Konrad, K., Zucker, N.L., \& Bulik, C. (2010). Psychological flexibility and symptom expression in Anorexia Nervosa. Manuscript submitted for publication.

Mizes, J. S., Christiano, B., Madison, J., Post, G, Seime, R., Varnado, P. (2000). Development of the Mizes Anorectic Cognitions Questionnaire-Revised: Psychometric properties and factor structure in a large sample of eating disorder patients. International Journal of Eating Disorder, 28, 415-421

Mintz, L. B., \& Betz, N. E. (1988). Prevalence and correlates of eating disordered behaviors among undergraduate women. Journal of Counseling Psychology, 35, $463-471$.

Mintz, L. B., \& Kashubeck, S. (1999). Body image and disordered eating among Asian American and Caucasian college students. Psychology of Women Quarterly, 23, 781-796.

Pettersen, G., Rosenvinge, J.H., \& Ytterhus, B. (2008). The 'double life' of bulimia: Patients' experiences in daily life interactions. Eating Disorders: The Journal of Treatment \& Prevention, 16, 204-211.

Pryor, T. L., Johnson, T., Wiederman, M. W., \& Boswell, D. L. (1995). The clinical significance of symptom denial among women with anorexia nervosa: Another disposable myth? Eating Disorders: The Journal of Treatment and Prevention, 3, 293-303.

Rawal, A., Park, R. J., \& Williams, M. G. (2010). Rumination, experiential avoidance, and dysfunctional thinking in eating disorders. Behaviour Research and Therapy, 48, 851-859. 
Rogers, N. A., \& Petrie, T. A. (2010). Body dissatisfaction, ethnic identity, disordered eating among African American women. Journal of Counseling Psychology, 57, 141-153.

Safer, D. L., Telch, C. F., \& Agras, W. S. (2001). Dialectical behavior therapy for bulimia nervosa. American Journal of Psychiatry, 158, 632-634.

Schmidt, U. \& Treasure, J. (2006). Anorexia nervosa: Valued and visible. A cognitiveinterpersonal maintenance model and its implications for research and practice. British Journal of Clinical Psychology, 45, 343-366.

Segal, Z. V., Teasdale, J. D., \& Williams, J. M. G. (2004). Mindfulness-based cognitive therapy: Theoretical rationale and empirical status. In S. C. Hayes, V. M. Follette, \& M. M. Linehan (Eds.), Mindfulness and acceptance: Expanding the cognitive behavioral tradition (pp. 45-65). New York: Guilford Press.

Smart, L., \& Wegner, D. (1999). Covering up what can't be seen: Concealable stigma and mental control. Journal of Personality and Social Psychology, 77(3), 474-486.

Stice, E., Nemeroff, C., \& Shaw, H. (1996). Test of the dual pathway model of bulimia nervosa: Evidence for dietary restraint and affect regulation mechanisms. Journal of Social and Clinical Psychology, 15(3), 340-363.

Striegel-Moore, R. H., \& Bulik, C. M. (2007). Risk factors for eating disorders. American Psychologist, 62, 181-198.

Teasdale, J. D., Moore, R. G., Hayhurst, H., Pope, M., Williams, S., \& Segal, Z. V. (2002). Metacognitive awareness and prevention of relapse in depression: Empirical evidence. Journal of Consulting and Clinical Psychology, 70, 275-287. 
Telch, C. F., Agras, W. S., \& Linehan, M. M. (2001). Dialectical behavior therapy for binge eating disorder. Journal of Consulting and Clinical Psychology, 69, 10611065.

Timko, C.A., Mooney, K., \& Juarascio, A. (2010). Change in eating and body related behaviors during the first year of university. Eating and Weight Disorders, 15, e93-e97.

Tylka, T. L. (2004). The relation between body dissatisfaction and eating disorder symptomatology: An analysis of moderating variables. Journal of Counseling Psychology, 51, 178-191.

Vandereycken, W., \& Van Humbeeck, I. (2008). Denial and concealment of eating disorders: A retrospective survey. European Eating Disorders Review, 16(2), 109114.

Vohs, K. D., Heatherton, T. F., \& Herrin, M. (2001). Disordered eating and the transition to college: A prospective study. International Journal of Eating Disorders, 29, 280-288.

Wegner, D. M. (1994). Ironic processes of mental control. Psychological Review, 101, 34-52.

Wismeijer, A. A. J., van Assen, M. A. L. M., Sijtsma, K., \& Vingerhoets, A. J. J. M. (2009). Is the negative association between self-concealment and subjective wellbeing mediated by mood awareness? Journal of Social and Clinical Psychology, 28, $728-748$. 
Wonderlich, S., Joiner, T., Keel, P., Williamson, D., \& Crosby, R. (2007). Eating disorder diagnoses: Empirical approaches to classification. American Psychologist, 62(3), 167-180. 
Table 1

Means, Standard Deviations, and Zero-Order Relations between all Variables

\begin{tabular}{lccccccc} 
& 1 & 2 & 3 & 4 & 5 & 6 & 7 \\
\hline 1. SCS & -- & & & & & \\
2. AAQ & $-.41^{* *}$ & -- & & & & \\
3. EAT-26 & $.19^{*}$ & $-.33^{* *}$ & -- & & & & \\
4. MAC-R & $.32^{* *}$ & $-.46^{* *}$ & $.52^{* *}$ & -- & & \\
5. Gender & $-.16^{*}$ & $-.14^{*}$ & .09 & .12 & -- & \\
6. Ethnicity & $.16^{*}$ & -.09 & -.09 & -.06 & -.02 & -- & \\
7. BMI & .05 & .03 & -.01 & .09 & -.04 & .03 & \\
& & & & & & & \\
$M$ & 28.18 & 71.51 & 8.31 & 61.37 & & & \\
SD & 8.48 & 8.93 & 8.37 & 14.87 & & \\
\hline
\end{tabular}

Note: $N=209,{ }^{*} p<.05,{ }^{* *} p<.01$, SCS $=$ Self-Concealment Scale; AAQ = Acceptance and Action Questionnaire; EAT = Eating Attitudes Test; MAC-R = Mizes Anorectic Cognition Questionnaire-Revised; BMI = Body Mass Index. 


\section{Table 2}

Linear Regression Analysis for Testing the Final Step of Mindfulness as a Mediator of the Association between Self-Concealment and Disordered Eating Symptoms.

\begin{tabular}{|c|c|c|c|c|c|c|}
\hline Variable & $\beta$ & $B$ & $S E B$ & $t$ & $p$ & Sobel z \\
\hline \multicolumn{7}{|c|}{ General Eating Disorder Pathology (EAT-26) } \\
\hline Gender & .06 & 1.21 & 1.42 & .79 & .429 & \\
\hline Ethnicity & -.13 & -2.11 & 1.13 & -1.87 & .063 & \\
\hline BMI & .00 & .00 & .12 & .06 & .949 & \\
\hline Self-Concealment (SCS) & .09 & .09 & .07 & 1.19 & .234 & \\
\hline Psychological Flexibility (AAQ-16) & -.29 & -.27 & .07 & -3.85 & .000 & \\
\hline \multicolumn{7}{|c|}{ Eating Disorder-related Cognition (MAC-R) } \\
\hline Gender & .10 & 3.61 & 2.32 & 1.56 & .121 & \\
\hline Ethnicity & -.13 & -4.00 & 1.85 & -2.17 & .031 & \\
\hline BMI & .10 & .29 & .19 & 1.56 & .121 & \\
\hline Self-Concealment (SCS) & .20 & .33 & .12 & 2.88 & .004 & \\
\hline Psychological Flexibility (AAQ-16) & -.38 & -.64 & .12 & -5.54 & .000 & $4.30 *$ \\
\hline
\end{tabular}

Note. $N=204$, All $p$-values were two-tailed. ${ }^{*} p<.001$, EAT $=$ Eating Attitudes Test, BMI = Body Mass Index, SCS = Self-Concealment Scale; AAQ = Acceptance and Action Questionnaire; MAC-R = Mizes Anorectic Cognition Questionnaire-Revised. 